\title{
A CONTRIBUIÇÃO DA LEGISLAÇÃO PARA A ORGANIZAÇÃO DO TRABALHO PEDAGÓGICO NA EDUCAÇÃO INFANTIL BRASILEIRA
}

\author{
Jaqueline Delgado Paschoal Paschoal ${ }^{1}$ \\ Carlos da Fonseca Brandão ${ }^{2}$
}

\section{RESUMO}

O objetivo deste estudo de caráter bibliográfico é analisar e discutir os avanços da legislação e o papel das políticas públicas voltadas para a educação infantil no Brasil. Ainda que o poder público, assim como a sociedade em geral e pesquisadores na área reconheçam que as instituições de atendimento à criança constituem espaços de cuidados e educação da criança, a realidade aponta para o descompasso entre o discurso das leis e sua concretização no cotidiano dessas instituições. Neste sentido, em primeiro lugar, traçamos a trajetória das leis e a inserção da educação infantil como primeira etapa da educação básica, para, em seguida, apresentar as recomendações do Ministério da Educação para a organização do trabalho pedagógico a partir da elaboração, planejamento, execução e avaliação do currículo na educação infantil. Os resultados da pesquisa apontam que houve um avanço significativo da legislação quando esta reconheceu a criança como cidadã, como sujeito de direitos, inclusive, de direito à educação de qualidade desde o nascimento. Por outro lado, as contradições nas diferentes determinações legais evidenciam os inúmeros desafios colocados para a efetivação desses direitos na vida das crianças e de suas famílias.

Palavras-Chave: Legislação; Educação Infantil; Trabalho Pedagógico.

\section{LAW OF CONTRIBUTION TO THE ORGANIZATION OF EDUCATIONAL WORK IN EARLY CHILDHOOD EDUCATION BRAZILIAN}

\begin{abstract}
The objective of this study is to analyze and bibliographical discuss progress of the legislation and the role of public policies for early childhood education in Brazil. Although the government as well as society in general and researchers in the field recognize that institutions of child care spaces constitute care and education of the child, the reality points to the gap between the discourse of the laws and their implementation in everyday these institutions. In this sense, first, we trace the trajectory of the laws and the inclusion of early childhood education as the first stage of basic education, then present the recommendations of the Ministry of Education to organize the pedagogical work from the development, planning, execution and evaluation of curriculum in early childhood education. The survey results indicate that there was a significant improvement of the legislation when it recognized the child as a citizen, as a subject of rights, including the rig dictions in the various legal determinations show the numerous challenges to the realization of those rights in the lives of children and their families.
\end{abstract}

Keywords: Law; Child Education; Pedagogical Work. 


\section{Introdução}

Desde as primeiras formas de atendimento institucional às crianças, há mais um século, até a primeira década do terceiro milênio, verifica-se um avanço significativo no que tange à legislação e às políticas públicas voltadas para a educação infantil no Brasil. Enquanto as primeiras instituições, em suas origens, propagaram a assistência e a custódia como única forma de cuidar da criança pequena, a partir da Constituição Federal de 1988, corroborada pela Lei de Diretrizes e Bases de 1996, a função educativa tornou-se elemento obrigatório na organização do trabalho pedagógico das escolas infantis brasileiras.

De modo geral, pode-se afirmar que diferentes fatores contribuíram para o reconhecimento, por parte da sociedade e do poder público, do direito da criança à educação desde o nascimento, tais como: o avanço da ciência e das pesquisas em todas as áreas do conhecimento nas últimas décadas; o aprimoramento da legislação; a própria mudança na estrutura familiar; e a reivindicação da população civil em relação à necessidade de expansão das instituições de cuidados e educação da criança pequena (OLIVEIRA, 2002). Apesar dos avanços registrados, verifica-se um descompasso entre as proposições legais e sua concretização nas escolas infantis.

Portanto, o objetivo deste estudo ${ }^{3}$ é analisar, criticamente, os avanços e os retrocessos da legislação, bem como, apresentar as recomendações das políticas públicas para a organização e implementação do trabalho pedagógico na educação infantil. O intuito é sinalizar para os inúmeros desafios colocados a partir das contradições previstas nas recomendações legais e seus diferentes encaminhamentos, de modo que as escolas infantis possam oferecer um atendimento de qualidade que unifique os cuidados e a educação da criança no cotidiano dessas instituições.

Quanto ao recorte temporal, este estudo se inicia no ano de 1988, data da Promulgação da Constituição Federal, que determina o dever do Estado em ofertar educação em creches e pré-escolas para crianças de zero a cinco anos de idade, e se estende até 2009, período em que foram propostas, pelo Ministério da Educação, as "Diretrizes Curriculares Nacionais para a Educação Infantil". Esse documento, além de orientar as políticas públicas, a partir de princípios, fundamentos e procedimentos definidos pela Câmara de Educação Básica do Conselho Nacional de Educação, também determina a elaboração, o planejamento, a execução e a avaliação das propostas pedagógicas e curriculares para essa etapa educacional.

Do ponto de vista metodológico, justifica-se tomar a Constituição Federal de 1988 como ponto de partida para a discussão por dois motivos: o primeiro, pelo fato de essa lei reconhecer o direito da criança à educação desde o nascimento e a obrigação do Estado em garantir esse direito; o segundo, por concordar com os estudos de Barretos (2003), que indicam que a Carta Constituinte recupera o caráter federativo da República, seriamente comprometido no regime autoritário, em virtude das medidas excessivamente concentradoras de recursos e de poder adotadas pelo governo central. Por meio dela, os municípios deixam de ser considerados apenas unidades administrativas, passando a entes federativos, aos quais são atribuídos recursos e autonomia em proporções maiores do que as estabelecidas em todas as constituições anteriores.

Além da competência própria para elaborarem as leis referentes aos interesses locais, os municípios adquirem competências compartilhadas com as demais instâncias, que passam a cobrir um vasto espectro de assuntos, entre os quais, a organização de seus respectivos sistemas de ensino. Os Estados também se beneficiam com a descentralização, pois recobram competências, recursos e maior autonomia, o que reforça o princípio do federalismo cooperativo (BARRETO, 2003). 
Para uma melhor organização da exposição, o presente estudo divide-se em duas seções, sendo que, na primeira, é realizada uma análise do avanço da legislação e de suas determinações no que tange à educação da criança em espaços institucionais; e, na segunda, são desenvolvidos alguns apontamentos sobre a importância da qualidade do atendimento e sobre o papel das políticas públicas nas recomendações acerca da organização do trabalho pedagógico das escolas infantis. É importante ressaltar que essas instituições são defendidas, aqui, como espaços fundamentais e necessários no cenário atual, já que complementam a educação da família, além de mediarem o processo de construção de conhecimentos, habilidades e identidade da criança e de seus profissionais.

\section{A Educação infantil e as recomendações legais.}

Até a década de setenta, a ausência de preocupação do poder público se configurou como pano de fundo das propostas de atendimento institucional voltadas para a educação infantil, já que as crianças de diferentes classes sociais eram submetidas a contextos de desenvolvimento diferentes, nas palavras de Kramer (1995). Enquanto as crianças de classes menos favorecidas eram atendidas com base em propostas de trabalho que partiam de uma ideia de carência e deficiência, as crianças das classes sociais mais abastadas recebiam uma educação que privilegiava a criatividade e a sociabilidade infantil. Em meados dos anos oitenta, a revisão do significado do papel das creches e pré-escolas possibilitou a substituição da função compensatória, defendida pelo discurso oficial, pela função educativa, graças aos movimentos dos diferentes setores da sociedade, tais como, organizações não-governamentais, pesquisadores da área da infância, comunidade acadêmica e população civil, que passaram a reconhecer a importância dessas instituições como espaços de socialização infantil e complementares à educação familiar. Do ponto de vista histórico, foi preciso quase um século para que a criança tivesse garantido seu direito à educação na legislação, pois, somente com a Carta Constitucional de 1988, esse direito foi, efetivamente, reconhecido.

De acordo com Bittar (2003, p. 30), o esforço coletivo dos diversos segmentos visava a assegurar, na Constituição, "[...] os princípios e as obrigações do Estado com as crianças". Assim, foi possível sensibilizar a maioria dos parlamentares e assegurar, na Constituição brasileira, o direito da criança à educação. A pressão desses movimentos na Assembléia Constituinte possibilitou a inclusão da creche e da pré-escola no sistema educativo, pois a Constituição Federal de 1988 estabelece, em seu em seu artigo 208, inciso IV: “[...] O dever do Estado para com a educação será efetivado mediante a garantia de oferta de creches e pré-escolas às crianças de zero a seis anos de idade" (BRASIL, 1988). A partir dessa lei, as creches, anteriormente vinculadas à área de assistência social, passaram a ser de responsabilidade da educação, pois foi tomado como orientação o princípio de que essas instituições não apenas cuidam das crianças, mas devem, prioritariamente, desenvolver um trabalho educacional.

Segundo estudos de Machado (2000), a Constituição de 1988 é um marco que inaugura uma nova era na história do atendimento à criança pequena em nosso país, pois, além de determinar a obrigatoriedade do Estado em disponibilizar vagas para todas as crianças, reconhece que estas são sujeitos de direitos e cidadãs.

Trata-se de não mais justificar uma função específica para as instituições de educação infantil e seus profissionais com base exclusivamente no direito das mulheres trabalhadoras, ou na retórica que justifica objetivos pedagógicos dessa ou daquela natureza, mas como um direito da criança (MACHADO, 2000, p. 07). 
A aprovação da Carta Constituinte possibilitou a reorganização de todo o sistema educacional, por meio de leis e políticas, e a distribuição de responsabilidades entre os níveis de governo federal, estaduais e municipais, "[...] bem como a delimitação expressa do montante dos recursos a serem aplicados no setor e seu direcionamento privilegiado por cada um dos níveis de governo (MACHADO, 2000, p. 8). Desta maneira, é dever do Estado disponibilizar vagas em instituições dos sistemas educacionais para todas as crianças, desde seu nascimento, seja qual for sua origem regional, social, racial ou étnica, e a despeito da opção religiosa ou política de seus pais (MACHADO, 2000).

Para Saviani (2013, p. 220), é importante que se faça distinção entre a proclamação de direitos e sua efetivação, pois "[...] se a educação é proclamada como um direito e reconhecida como tal pelo poder público, cabe a este poder a responsabilidade de prover os meios para que o referido direito se efetive." Neste sentido, a Constituição (1988) possibilitou a implementação de políticas educativas, sobretudo, pelas Emendas Constitucionais inseridas no texto legal nas duas últimas décadas, no entanto, permanecem ainda "fortes limitações, mantendo-se a marca que atravessa toda a história da educação brasileira: a precariedade" (SAVIANI, 2013 p. 221). Dessa maneira, desde a infraestrutura das escolas, os baixos salários, a ausência de materiais, assim como, as condições adversas que impossibilitam uma atuação mais qualificada do professor contribuem para a perpetuação de uma escola bastante aquém da desejada, devido, principalmente, à "[...] desídia das autoridades em assumir, na prática, a prioridade conferida à educação no texto da Constituição" (SAVIANI, 2013, p. 221).

Dois anos após a aprovação da Constituinte, foi sancionado o Estatuto da Criança e do Adolescente - Lei 8.069/90, que, ao regulamentar o art. 227 da Constituição Federal, inseriu as crianças no mundo dos direitos humanos. De acordo com esse documento, a criança e o adolescente gozam de todos os direitos fundamentais inerentes à pessoa humana, já que cabe à sociedade possibilitar-lhes o acesso às oportunidades e facilidades, a fim de lhes facultar o desenvolvimento físico, mental, moral, espiritual e social, em condições de liberdade e dignidade (BRASIL, 1990). Portanto, é dever da família, da comunidade e da sociedade em geral assegurar a efetivação desses direitos referentes à vida, à saúde, à alimentação, à educação, ao esporte, ao lazer, à profissionalização, à cultura, à dignidade, ao respeito, à liberdade e à convivência familiar e comunitária (BRASIL, 1990).

Para Ferreira (2000, p. 184), essa lei é mais do que um simples instrumento jurídico, pois possibilitou um novo olhar sobre o direito da criança de ser criança, ou seja, "[...] direito ao afeto, direito de brincar, direito de querer, direito de não querer, direito de conhecer, direito de sonhar. Isso quer dizer que são atores do próprio desenvolvimento." Ao se reconhecer a criança e o adolescente como pessoas em condições peculiares de desenvolvimento, estes não podem, segundo a autora, ser confundidos como adultos, haja vista que "não possuem o mesmo conhecimento sobre a dinâmica e o funcionamento da sociedade e de suas instituições; não possuem o mesmo poder de negociação, e organização e de reivindicação de seus direitos" (FERREIRA, 2000, p. 184).

Sobre o direito à educação, o ECA destaca, no capítulo IV, a igualdade de condições para o acesso e a permanência na escola, tanto para a criança como para o adolescente. No artigo 54, a lei determina o atendimento, em creche e pré-escola, a crianças de zero a seis anos de idade (BRASIL, 1990).

Além da Constituição Federal de 1988 e do Estatuto da Criança e do Adolescente de 1990, destaca-se a Lei de Diretrizes e Bases da Educação Nacional de 1996, que, ao tratar da composição dos níveis escolares, reconhece a educação infantil como primeira 
etapa da educação básica, ao destacar que "a educação escolar compõe-se de: I - educação básica, formada pela educação infantil, ensino fundamental e ensino médio; II - educação superior" (BRASIL,1996). Embora apresente somente três artigos, de forma sucinta e genérica, no que tange a esse nível de ensino, avança significativamente, pois define, no art. 29, que a finalidade dessa etapa educacional é "[...] promover o desenvolvimento integral da criança até seis anos de idade, em seus aspectos físico, psicológico, intelectual e social, complementando a ação da família e da sociedade" (BRASIL, 1996).

No art. 30, que foi alterado pela Lei $\mathrm{n}^{\circ} 11.114 / 2005^{4}$, utiliza a nomenclatura "creche" e "pré-escola", apenas para designar a faixa etária das crianças, já que determina que a educação infantil "[...] será oferecida em creches ou equivalentes, para crianças de até três anos de idade; pré-escolas para crianças de quatro a cinco anos de idade" (BRASIL, 1996). Outro avanço que a lei traz refere-se à avaliação, que não tem a finalidade de promoção ou retenção da criança, pois, em seu art. 31, estabelece que "[...] a avaliação far-se-á mediante acompanhamento e registro do seu desenvolvimento, sem o objetivo de promoção, mesmo para o acesso ao ensino fundamental (BRASIL, 1996).

Para o Ministério da Educação, o tratamento dos vários aspectos como dimensões do desenvolvimento e não como áreas separadas foi fundamental, pois isso "[...] evidencia a necessidade de se considerar a criança como um todo, para promover seu desenvolvimento integral e sua inserção na esfera pública" (BRASIL, 2006, p. 10).

Quanto à formação de professores para atuar com essa faixa etária, a LDB (1996) avançou, principalmente, quando excluiu a participação de professores leigos do sistema de ensino, estabeleceu a formação mínima na modalidade normal e destacou que essa formação deverá acontecer em nível superior, em cursos de licenciatura, de graduação plena, em universidades e institutos superiores de educação, admitida como formação mínima para o exercício do magistério na educação infantil, e nas quatro primeiras séries do ensino fundamental, oferecida em nível médio, na modalidade normal (BRASIL, 1996).

Desse modo, verifica-se um avanço importante no que tange aos direitos da criança à educação, uma vez que a educação infantil, além de ser considerada a primeira etapa da educação básica, é um direito da criança e tem o objetivo de proporcionar condições adequadas para o desenvolvimento de seu bem-estar e a ampliação de suas experiências.

Oliveira e Rubiano (2000, p.48) ressaltam que, embora essa etapa educacional tenha sido incluída nos textos legais, o que possibilitou a substituição da função assistencial, até então presente nas diferentes formas de atendimento, pelo caráter pedagógico, tanto a Constituição de 1988 como a LDB de 1996 apresentam “[...] em certos momentos, uma visão de sistema educacional muito comprometida com a noção de escola e de ensino, com possíveis implicações sobre os custos do atendimento." Para as autoras, como parte integrante da educação básica, essas instituições constituem estatuto de unidade escolar e de modalidade de ensino, assim, conteúdos curriculares devem ser trabalhados com a criança, o que pode ser entendido, por seus profissionais, como escolarização e antecipação do ensino regular.

Ao analisar a concretização das leis no cotidiano das escolas brasileiras, Nascimento (2011, p. 151) aponta que, embora as diferentes políticas públicas para a pequena infância tenham se pautado "[...] pela concepção de criança como sujeito de direitos e ator social", não é esse o quadro que se apresenta para a consolidação dessa cidadania. Um dos principais paradoxos encontra-se no texto da Lei de Diretrizes e Bases da Educação Nacional (1996), que descentralizou para os municípios a responsabilidade pela educação infantil e pelo ensino fundamental, entretanto, o Estado como federação não garante a distribuição igualitária de recursos e a manutenção destes nos diferentes níveis de ensino. 
O Fundo de Manutenção e Desenvolvimento do Ensino Fundamental e de Valorização do Magistério (Fundef) - Lei 9.424/9 - reforçou essa desigualdade, de acordo com Nascimento (2011, p. 152), haja vista que “[...] financiava e valorizava o ensino fundamental, de maneira que o financiamento para a educação infantil, nos municípios, concorria com o destinado ao ensino médio", sobrando, assim, recursos parcos para esse nível de ensino. O Plano Nacional de Educação - PNE, Lei 10.172/01, reconheceu outro problema concernente à oferta "[...] desequilibrada em relação às creches e as pré-escolas, visto que havia poucos dados disponíveis sobre a primeira e uma quantidade maior sobre a segunda", além da proposição de ampliação da melhoria do atendimento com uma porcentagem maior para a pré-escola (NASCIMENTO, 2011, p. 153). Na realidade, havia uma tendência à universalização ${ }^{5}$ do atendimento apenas para as crianças de quatro a seis anos de idade, problema esse resolvido pela Emenda Constitucional de número 53, aprovada em 2006.

\begin{abstract}
Alterado pela Lei $\mathrm{n}^{\mathrm{o}}$ 11.494/07, que instituiu o Fundo Nacional de Desenvolvimento da Educação Básica e de Valorização do Magistério (Fundeb), o recurso para o financiamento da educação infantil foi garantido legalmente, ainda que, num primeiro momento, as creches tivessem sido excluídas desse Fundo, fato que gerou grande mobilização dos movimentos sociais e que apontava para a visão fragmentada da etapa por parte de políticos e legisladores (NASCIMENTO, 2011, p. 153).
\end{abstract}

É importante ressaltar que o Plano Nacional de Educação (2001), apesar de ter objetivado a redução das desigualdades sociais e regionais, no que diz respeito à entrada $\mathrm{e}$ à permanência da criança e do adolescente no ensino público, princípio que se aplica à educação infantil, de acordo com Barreto (2003), não garantiu o acesso de crianças das classes menos favorecidas. Uma análise dessa autora, realizada em estudo anterior, destaca que "[...] as instituições de educação infantil no Brasil, devido à forma como se expandiram, sem os investimentos técnicos e financeiros necessários, apresentam ainda, padrões, bastante aquém dos desejados" (BARRETO, 2003, p. 25). Isso quer dizer que problemas de diferentes nuances, como a ausência de propostas pedagógicas que integram cuidados à educação das crianças, assim como a inadequação de espaços físicos e materiais insuficientes, professores com baixa qualificação, entre outros, estão ainda presentes na grande maioria das escolas infantis brasileiras.

A questão do acesso e a qualidade do atendimento também contribuem para a fragilidade dos serviços oferecidos às crianças e suas famílias, já que mesmo tendo havido, nas últimas décadas, uma significativa expansão da oferta, a entrada das crianças em creches ainda é bastante limitada, sobretudo porque as de famílias de baixa renda estão tendo menores oportunidades do que as de nível socioeconômico mais elevado, segundo estudo anterior de Barreto (1998). A busca pela qualidade envolve outras questões complexas, segundo essa autora, como o projeto educativo das instituições, a formação e a valorização do professor e recursos financeiros destinados a essa faixa etária, sendo necessário, contudo, garantir que esses recursos sejam, efetivamente, empregados nesse nível de ensino.

Brandão (2007), ao analisar as metas do PNE (2001) para a educação infantil, ressalta que, principalmente, a que trata da ampliação da oferta de atendimento às crianças dificilmente será alcançada, pois a elevação do número de vagas exige um investimento financeiro bastante significativo para esse nível de ensino. 
superávit primário para pagamento de juros, encargos e serviços da dívida externa brasileira, torna-se difícil acreditar que os mesmos serão efetivados (BRANDÃO, 2007, p. 81).

Em relação ao atendimento com qualidade, Brandão (2007) esclarece que, embora não haja dúvida de que o cumprimento de tal meta só trará benefícios às crianças, o problema é que a adoção progressiva do atendimento em tempo integral a inviabiliza, uma vez que "[...] corre-se o risco de nunca virmos a ter tal atendimento, visto que ainda não conseguimos, sequer, adotá-lo para as crianças do Ensino Fundamental" (BRANDÃO, 2007, p. 82). A meta que propõe a realização de estudos sobre o custo da educação infantil, com o intuito de melhorar a qualidade do atendimento desse nível de ensino é analisada por Brandão (2007) e, segundo ele, para atingir essa meta seria necessário, primeiramente, definir quais são os parâmetros de qualidade. Desse modo, o autor enfatiza que é primordial que se atinja primeiro "[...] uma série de disposições postas no conjunto das metas e objetivos estabelecidos por esse PNE para a educação infantil" (BRANDÃO, 2007, p. 84). No que se refere à questão da oferta e do atendimento, nesse nível de ensino, o autor assevera que, dificilmente, tais metas serão alcançadas até a vigência desse documento, mesmo que haja colaboração das diversas esferas do Poder Público.

Na contramão das metas estabelecidas pelo Plano Nacional de Educação (2001) sobre o direito de todas as crianças à educação, em todos os níveis educacionais, a Emenda Constitucional $n^{\circ} 59 / 2009$ tornou o ensino obrigatório dos quatro os dezessete anos a partir de $2016^{6}$, excluindo a faixa etária de zero a três anos de idade ${ }^{7}$. Embora seja uma estratégia para assegurar o direito à educação, de maneira ampliada, para todas as crianças a partir dos quatro anos, principalmente, as das camadas mais pobres da população, fragmenta a educação infantil, já que "[...] abala a concepção de creche como espaço legítimo de educação e cuidado da criança pequena" (NASCIMENTO, 2011, p. 154). Nesse sentido, o paradoxo se encontra em "[...] duas medidas legais diferentes para uma mesma etapa de educação que dividem a etapa em duas, recuperando, de certa maneira, sua divisão histórica (p. 155).

É importante ressaltar que a referida Emenda contradiz, também, a Lei 11.114/05, que altera a artigo 30 da LDB de 1996, ao dividir a educação infantil em creches e préescolas, apenas no que tange ao corte etário.

Não há dúvida de que atribuir característica antecipatória à educação de crianças de 4 e 5 anos fará com que a identidade da educação infantil, em construção porque recentemente formalizada, tenda a se fragmentar. Em outras palavras, serão as crianças de 4 e 5 anos identificadas com as propostas pedagógicas do ensino fundamental e perderão seu direito a uma educação cujos eixos são a brincadeira e a interação (DNCEI, Art. $9^{\circ}$ )? (NASCIMENTO, 2011, p. 155).

Para Nascimento (2001, p. 155), a interpretação equivocada da EC/59 pode levar a "[...] pré-escola a ser compreendida como antecipação da escola, como ocorreu nos anos de 1970 e 1980, por ocasião da formalização da educação pré-escolar no Brasil." A opção por colocar ou não os filhos na escola infantil será apenas das famílias com crianças até três anos, já que a partir dessa faixa etária passa a ser obrigatório o ingresso dos pequenos na pré-escola. Daí a importância de se priorizar uma formação altamente qualificada de professores para lidar com essa etapa educacional, no sentido de possibilitar a esses profissionais uma compreensão teórica e metodológica que abarque os cuidados e a educação, de maneira integrada, da criança de zero a cinco anos de idade. 
A análise apresentada, até aqui, revela avanços da legislação brasileira, já que, por um lado, está assegurada uma concepção de criança cidadã, mas, inversamente, muitos retrocessos acompanham a trajetória legal das instituições de atendimento à criança, já que a determinação das leis não garante que a realidade da população infantil tenha mudado. Assim, é importante considerar os inúmeros desafios colocados para a consolidação desses direitos, sobretudo no que diz respeito à qualidade do atendimento oferecido às crianças e suas famílias.

\section{A qualidade do atendimento como direito da criança: o papel das políticas para a educação infantil brasileira.}

A discussão sobre a qualidade dos serviços prestados à criança pequena, em espaços educacionais, acompanhou, de certa forma, as mudanças ocorridas no país nas duas últimas décadas, pois ocupou um espaço significativo no debate educacional, direcionando políticas implantadas no quadro das reformas educacionais. Para Corrêa (2003, p. 86), os estudos sobre o fenômeno educacional ao mesmo tempo em que discutem e questionam a função da escola como espaço de formação da criança, também "[...] apontam novos métodos, estratégias, meios etc. para uma melhoria da assim chamada qualidade da educação.” Se, por um lado, essa questão se aplica às políticas educacionais que justificam suas respectivas reformas com base nessa qualidade, por outro, o fato de diferentes entendimentos perpassarem o próprio conceito de qualidade impossibilita uma definição mais precisa do termo. Na realidade, a complexidade de se definir, como verdade absoluta, o que seria a qualidade dos serviços prestados acaba por reforçar uma visão bastante diversa nas propostas e políticas apresentadas, pelos diferentes setores da sociedade, sobretudo, no campo educacional. (CORRÊA, 2003).

Segundo estudos de Dahlberg; Moss; Pence (2003), do ponto de vista histórico, o discurso sobre a qualidade é um produto do pensamento iluminista, pois concebe o mundo por meio de uma lente modernista, sobretudo, ao adotar a mesma linguagem da qualidade total à linguagem da escola infantil e ao considerar a "[...] criança como um vaso vazio, a qual deve ser preparada para aprender e para a escola, e ser ajudada em sua jornada de desenvolvimento" (p. 119). Para os autores:

O conceito de qualidade em relação às instituições dedicadas à primeira infância é irremediavelmente modernista, é parte do sonho cartesiano de certeza e da ambição de progresso e verdade do Iluminismo. Refere-se a uma busca por critérios definitivos e universais, certeza e ordem ou não se refere a nada (DAHLBERG; MOSS; PENCE, 2003, p.142).

A importância da qualidade no contexto das escolas infantis pode ser entendida em relação à busca modernista pela ordem e pela certeza, fundamentadas na objetividade e na quantificação, já que esse discurso faz parte da vida econômica e política da sociedade contemporânea. Fruto de um capitalismo desordenado, o consumo passa a ser o principal enfoque da economia.

Os bens ainda são manufaturados, mas o intercâmbio de serviços e de informações, justamente com a aprendizagem para toda a vida, tornam-se cada vez mais importantes. Computadores e telecomunicações são as tecnologias definidoras. A composição e a natureza do emprego estão mudando; surgem novos tipos de trabalho baseados em novas habilidades, enquanto outros desaparecem (DAHLBERG; MOSS; PENCE, 2003, p. 119). 
A emergência do discurso da qualidade teve seu apogeu no início da década de oitenta, implementado de diversas maneiras, incluindo pesquisas, medidas, padrões e diretrizes sobre a boa prática dos professores, segundo Dahlberg; Moss; Pence (2003). Ao refutarem o discurso da objetividade e da racionalidade, os autores postulam que a qualidade dos serviços dedicados à primeira infância se baseia em valores, crenças e interesses, em detrimento de uma realidade objetiva e universal. Por isso, há a necessidade de se buscar outras respostas, “[...] por exemplo, por meio da descentralização do poder das instituições fundamentais do estado-nação; buscar novas instituições para a prática da democracia" (p. 120). Desse modo, olhar para além do pós-modernismo possibilita novas maneiras de entender o mundo, incluindo as crianças pequenas e suas instituições, já que o discurso da construção de significado se refere à "[...] construção e ao aprofundamento do entendimento da instituição dedicada à primeira infância e a seus projetos, em particular o trabalho pedagógico" (DAHLBERG; MOSS; PENCE, 2003, p. 143).

Em se tratando das escolas infantis brasileiras, a preocupação com a baixa qualidade dos serviços oferecidos, segundo Campos; Füllgraf; Wiggers (2006, p. 89), despontou logo após os primeiros estudos sobre as condições de funcionamento, sobretudo das creches, denunciarem "[...] as precárias condições dos prédios e equipamentos, a falta de materiais pedagógicos, a baixa escolaridade e a falta de formação dos educadores, a ausência de projetos pedagógicos e as dificuldades de comunicação com as famílias". As autoras afirmam que tratar de uma concepção democrática de qualidade pressupõe considerar o tipo de atendimento oferecido às criança e suas famílias. A falta de qualidade nesses serviços, historicamente, possibilitou a revisão do seu significado e $\mathrm{o}$ reconhecimento do "[...] respeito aos direitos da criança, em primeiro lugar, para que fosse possível mostrar a legisladores e administradores a importância da garantia de um patamar mínimo de qualidade para creches e pré-escolas" (CAMPOS; FÜLLGRAF; WIGGERS, 2006, p. 90).

De acordo com as autoras, foi, principalmente, no âmbito da atuação de grupos ligados à universidade e aos profissionais da educação, que se formularam os princípios que seriam acolhidos pela Constituição Federal de 1988 e que foram, em grande parte, mantidos na Lei de Diretrizes e Bases da Educação Nacional- LDB de 1996.

\footnotetext{
A principal mudança foi a definição da educação infantil como primeira etapa da educação básica o que significou, na prática, a exigência de que prefeituras e outras instâncias governamentais transferissem para o âmbito dos órgãos de educação a responsabilidade pelas redes de creche (CAMPOS; FÜLLGRAF; WIGGERS, 2006, p. 90).
}

O Ministério da Educação desempenhou papel importante nesse período, sobretudo, na formulação de diretrizes para a educação infantil no sentido de reiterar a importância da qualidade do atendimento oferecido às crianças e suas famílias. Desse modo, nas duas primeiras décadas após aprovação da LDB (1996), diferentes documentos foram publicados, em parceria com as secretarias municipais de educação, com o objetivo de garantir políticas públicas para essa faixa etária, dentre os quais pode-se destacar: "Critérios para um atendimento em creches que respeite os direitos fundamentais da criança", de 1995, que foi organizado por meio de doze critérios para a unidade creche e por um vídeo, intitulado "Nossa creche respeita criança"; "Subsídios para o credenciamento e o funcionamento das instituições de educação infantil ${ }^{8 \%}$, de 1998, que contribuiu, significativamente, para a formulação de diretrizes e normas para a educação da criança pequena em todo o país; e o "Referencial Curricular Nacional para a Educação 
Infantil”, também de 1998, cujo objetivo foi contribuir para a implementação de práticas educativas de qualidade no interior das instituições de atendimento à criança e servir como um guia de reflexão de cunho educacional sobre os objetivos, conteúdos e orientações didáticas para os profissionais que atuam com crianças de zero a cinco anos de idade.

Com o objetivo de propiciar o cumprimento do preceito constitucional da descentralização administrativa, principalmente no que tange à organização dos sistemas de ensino de cada região, e como forma de garantir um trabalho pedagógico de qualidade nas escolas infantis, o MEC apresentou a "Política Nacional de educação infantil: pelo direito da criança de 0 a 6 anos à educação", no ano de 2006. Este documento define como principais objetivos para essa etapa educacional: a expansão da oferta de vagas, o fortalecimento das instâncias competentes e, sobretudo, a garantia de uma "concepção de educação e cuidado como aspectos indissociáveis das ações dirigidas às crianças e a promoção da melhoria da qualidade do atendimento em instituições de educação infantil" (BRASIL, 1996 a, p. 10). Assim, ao destacar a integração entre educar e cuidar, na atuação junto às crianças, essa política aponta que as instituições de atendimento constituem um espaço “[...] diferenciado e complementar à ação da família, o que implica uma profunda, permanente e articulada comunicação entre elas" (BRASIL, 2006, p. 17).

O documento de 2006, ao traçar os objetivos para a organização das escolas infantis, ressalta que as instituições devem elaborar, implementar e avaliar suas propostas pedagógicas, explicitando concepções e definindo diretrizes referentes à metodologia de trabalho e ao processo de aprendizagem infantil. A participação dos professores nesse processo é condição necessária para a construção de um trabalho coletivo que possibilite "[...] atendimento integral à criança, considerando seus aspectos físico, afetivo, cognitivo, sociocultural, bem como as dimensões lúdica, artística e imaginária” (BRASIL, 2006, p. 20). Esse documento, além de prever padrões mínimos de infraestrutura para o funcionamento adequado das escolas infantis, também assegura a valorização dos professores ao promover a participação dos mesmos em programas de formação inicial e em exercício, garantindo-lhes, nas redes públicas, a inclusão nos planos de cargos e salários do magistério.

De modo a atender o previsto na Política Nacional de educação infantil, o Ministério da Educação publicou, também em 2006, o documento intitulado: "Parâmetros Nacionais de Qualidade para a educação infantill"- volumes 1 e $2^{9}$, com o objetivo de estabelecer parâmetros de qualidade locais, com base nos padrões de referência nacional para os sistemas de ensino, sobretudo no que se refere à organização e funcionamento das escolas infantis. Ao definir esses padrões, a preocupação não foi apontar um padrão mínimo nem máximo, mas “[...] os requisitos necessários para uma educação infantil que possibilite o desenvolvimento integral da criança até cinco anos de idade, em seus aspectos físico, psicológico, intelectual e social" (BRASIL, 2006 b, p. 09). Esse documento destaca, como padrão de referência para um atendimento de qualidade, quesitos necessários para a construção de uma proposta pedagógica que respeite os direitos da criança, tais como: integração entre cuidados e educação; trabalho pedagógico que complemente a educação da família; atividades orientadas que promovam diferentes aprendizagens infantis; reconhecimento da identidade pessoal das crianças, de suas famílias, dos professores e de outros profissionais; inclusão das crianças com necessidades educacionais especiais; autonomia das instituições para a elaboração das propostas pedagógicas; formação adequada de professores e gestores; e espaços, materiais e equipamentos adequados para o pleno funcionamento das escolas infantis.

Para Nascimento (2011 p. 151), as políticas públicas para a educação infantil, desde os documentos publicados pelo MEC na primeira metade da década de 1990, “[...] os 
chamados documentos das carinhas, até a Política Nacional, de 2006, têm buscado pautarse pela concepção de criança como sujeito de direitos e ator social." Desse modo, os documentos apresentados pelo Ministério da Educação indicam, no conteúdo dos textos, uma concepção de criança cidadã, sujeito de direitos, sobretudo no que diz respeito ao direito à educação desde o nascimento. Portanto, a escola infantil é tratada, nos documentos oficiais, como espaço de promoção da aprendizagem e do desenvolvimento integral da criança, uma vez que "[...] é nas interações, relações e práticas cotidianas que vivencia, constrói sua identidade pessoal e coletiva" (BRASIL, 2009, p. 01).

A Resolução $n^{\circ}$ 5, de 17 de dezembro de 2009, que fixa as Diretrizes Curriculares Nacionais para a educação infantil ${ }^{10}$, ao estabelecer normas para a construção e implementação de propostas pedagógicas para as escolas infantis, determina que os seguintes princípios sejam observados e respeitados:

Art. 6- I: Éticos: da autonomia, da responsabilidade, da solidariedade e do respeito ao bem comum, ao meio ambiente e às diferentes culturas, identidades e singularidades; II- Políticos: dos direitos de cidadania, do exercício da criticidade e do respeito à ordem democrática; III- Estéticos: da sensibilidade, da criatividade, da ludicidade e da liberdade de expressão nas diferentes manifestações artísticas e culturais (BRASIL, 2009, p. 02).

Ao reiterar as orientações das políticas para a infância, esse documento destaca que o projeto pedagógico é o "[...] plano orientador das ações da instituição e define as metas que se pretende para a aprendizagem e o desenvolvimento das crianças que nela serão educadas e cuidadas" (BRASIL, 2009, p. 13). Assim, o currículo deve ser entendido como um conjunto de práticas que busca articular as experiências e os saberes das crianças com os conhecimentos que fazem parte do patrimônio cultural, artístico, ambiental, científico e tecnológico, de modo a promover seu desenvolvimento pleno (BRASIL, 2009).

Zabalza (1998) destaca que as escolas infantis, assim como as de qualquer outro nível de ensino, constituem espaços primordiais da vida das crianças, principalmente porque complementam a educação da família, assim, ao oferecerem um atendimento de qualidade, contribuem para a construção da autonomia infantil e para o desenvolvimento das muitas linguagens da criança. A qualidade que se espera, pelo menos, no que se refere às escolas, "não é tanto um repertório de traços que se possuem, mas sim, algo que vai sendo alcançado; é algo dinâmico, algo que se constrói dia a dia e de maneira permanente" (ZABALZA, 1998, p. 32). Para esse autor, existe uma série de variáveis que podem interferir nesse processo, ou seja, condições organizacionais, qualidade do pessoal, definição clara dos objetivos educativos e didáticos da escola, sistema eficaz de supervisão e de avaliação, planejamento adequado, relação positiva com a comunidade e relação próxima com as famílias.

É importante destacar que a qualidade deve se constituir como pano de fundo na ação dos professores, principalmente, no que tange ao trato com as crianças e ao "[...] respeito à dignidade e aos direitos das crianças, consideradas nas suas diferenças individuais, sociais, econômicas, culturais, étnicas, religiosas etc.; direito das crianças a brincar, como forma particular de expressão, pensamento, interação e comunicação infantil (BRASIL, 1998, p.13). A autonomia, a identidade e a competência também estão ligadas ao processo de desenvolvimento da criança e à concepção de uma educação de qualidade. Enquanto a identidade infantil só se concretiza por meio do amadurecimento de uma autoimagem positiva e do sentimento de confiança em si mesma e nas próprias capacidades, as competências se tornam possíveis a partir da construção da capacidade de interiorização e utilização dos sistemas simbólicos e culturais (ZABALZA, 1998). 
Dessa maneira, Zabalza (1998) aponta três objetivos considerados fundamentais na busca pela qualidade do atendimento às crianças e suas famílias, que são: 1) Uma escola para a criança: a atenção é concentrada na identidade da criança, na sua condição de sujeito de direitos diversos, na consciência de si mesma, na íntima relação com a sua família e sua cultura de origem; 2) Uma escola das experiências e dos conhecimentos: a atenção concentra-se em alguns conteúdos significativos da experiência - a educação linguística, motora, musical e científica; 3) Uma escola baseada na participação e integrada com a comunidade: presta-se muita atenção à relação com as famílias, à gestão social e também à consciência de desejar obter uma cidade autenticamente educadora. Essa é uma questão importante, já que as crianças, quando expostas a diferentes situações de interação social, têm seu universo de significados ampliado, sobretudo quando participam de contextos coletivos que primam pela qualidade.

Mesmo antes de se expressarem por meio da linguagem verbal, as crianças são capazes de interagir a partir de outras linguagens, seja a corporal, gestual, plástica, simbólica e lúdica. Nesse contexto, a ênfase na apropriação de significados e na ampliação progressiva de conhecimentos, de modo contextualizado, com base em estratégias apropriadas às diferentes fases do desenvolvimento infantil, é condição fundamental para a consolidação de padrões de qualidade (BRASIL, 2009). Assim, o desafio posto é garantir a concretude das proposições legais e das recomendações das políticas no cotidiano das escolas infantis brasileiras.

Para ilustrar essa questão, Rosemberg (2003) utiliza o mito da maldição de Sísifo $^{11}$, ao analisar as políticas nacionais de educação infantil no Brasil. Para essa autora, houve um avanço importante do poder público e da sociedade em relação ao direito da criança à educação em espaços coletivos, no entanto, "“...] as políticas de educação infantil contemporâneas, nos países subdesenvolvidos, têm sido fortemente influenciadas por modelos ditos "não formais", reduzido investimento público, propugnados por organismos multilaterais, que têm ajudado a dar um empurrãozinho para baixo, no caso do Sísifo brasileiro" (ROSEMBERG, 2003, p. 177). Segundo a autora, até o final dos anos 1960, os modelos institucionais implantados nos países desenvolvidos e subdesenvolvidos priorizavam dois modelos de atendimento, sendo um mais assistencial, para as creches e similares, cuja população era, principalmente, formada por crianças pobres, enquanto o segundo modelo, os jardins de infância, destinavam-se a crianças de origem econômica mais favorecida.

\footnotetext{
Esse modelo de educação infantil foi sendo elaborado gradualmente e divulgado, inicialmente, pela UNESCO e UNICEF, através de diferentes canais: missões em diferentes países, publicações, seminários internacionais e regionais, assessoria de especialistas desses organismos, especialmente da UNICEF, junto a ministérios nacionais; em menor escala, alguns projetos receberam financiamento, especialmente nos países africanos (ROSEMBERG, 2003, p.179).
}

O empurrão para baixo, seguindo a maldição da lenda de Sísifo, aconteceu em função de o Brasil ter acolhido esses modelos, sobretudo, no que tange aos investimentos de baixo custo, o que inclui desde a participação de professores leigos, até "[...] espaços improvisados, mesmo quando especificamente construídos para a educação infantil; material pedagógico, também improvisado ou escasso, como brinquedos, livros, papéis e tinta" (ROSEMBERG, 2003, p. 179).

O modelo incorporou uma articulação perversa entre espaço inadequado, precariedade de material pedagógico e ausência de qualificação profissional do 
(a) educador (a), redundando em ambientes educacionais pouco favoráveis ao enriquecimento das experiências infantis. Essa nova concepção atingiu o Brasil durante o período de ditadura militar, quando encontrou terreno fértil para sua proliferação e recriação (ROSEMBERG, 2003, p. 181).

A subida para a montanha, no caso do Sísifo brasileiro, iniciou-se com a inserção da educação infantil como direito da criança na Carta Constitucional de 1988 e como "[...] como instrumento para igualdade de oportunidades de gênero, na medida em que apóia o trabalho materno extra-doméstico", segundo Rosemberg (2003, p. 183). Nesse sentido, o Ministério da Educação junto a COEDI (Coordenação de Educação Infantil) apresentaram uma nova proposta nacional para essa etapa educacional, não só afastando os modelos de baixo custo, mas priorizando uma proposta de qualidade dos serviços oferecidos a todas as crianças, independente de origem e classe social ${ }^{12}$.

\footnotetext{
Essas propostas do MEC foram elaboradas com participação de segmentos sociais - universidades, movimentos sociais, partidos políticos, associações profissionais, usuários - que já haviam acumulado um repertório de conhecimentos e experiências sobre esse setor das políticas sociais e constituído o consenso de empurrar Sísifo até o topo da montanha e lá mantê-lo: EI com qualidade, para todas as crianças cujas famílias por ela optassem (ROSEMBERG, 2003, p. 183).
}

Desde a aprovação da carta constitucional, no final da década de oitenta, até os dias atuais, passados vinte e seis anos de sua promulgação, assistimos a obrigatoriedade das leis e significativas contribuições das políticas públicas para a pequena infância. Por outro lado, presenciamos, também, em diferentes momentos da história, a contribuição das políticas para a subida ou para o declínio de Sísifo, sobretudo por parte das administrações governamentais, que, influenciadas pelo Banco Mundial, nas duas últimas décadas, priorizaram, segundo Rosemberg (2003), investimentos públicos no ensino fundamental.

Para finalizar, é importante ressaltar que, apesar do consenso da sociedade civil e do poder público sobre o direito da criança à educação desde o nascimento, o desafio é consolidar, efetivamente, não só os direitos no âmbito educativo, mas garantir todos os outros previstos nas leis para todas as crianças brasileiras. Dessa maneira, repensar o atendimento oferecido às populações infantis, em espaços coletivos, requer um olhar cuidadoso e um compromisso permanente das diferentes instâncias sociais, ou seja: do Estado, de oferecer políticas que garantam, na prática, a efetivação desses direitos; da sociedade, de reconhecer a relevância das instituições de educação infantil como complementares à educação familiar; da família, de assumir, verdadeiramente, a educação dos filhos e compartilhar essa educação em espaços que enriqueçam e ampliem as experiências infantis; dos gestores, professores e demais envolvidos no cotidiano das escolas infantis, de se comprometerem em busca da formação continuada e de um atendimento altamente qualificado no que diz respeito à organização do trabalho com as crianças pequenas.

\section{Referências}

BARRETO, Ângela M. R. Situação atual da educação infantil no Brasil. In: BRASIL. Ministério da Educação e do Desporto. Subsídios para o credenciamento e funcionamento de instituições de educação infantil. v. 2. Coordenação Geral de educação infantil. Brasília: MEC/SEF/COEDI, 1998. 
Ângela M. R. A educação infantil no contexto das políticas públicas. Revista

Brasileira de Educação - Associação Nacional de Pós-Graduação e Pesquisa em Educação, Rio de Janeiro, Campinas, SP: Autores Associados, n. 24, p. 53-65, set./out./nov./dez. 2003.

BRASIL. Constituição da República Federativa do Brasil. Brasília, DF: Senado Federal, 1988, 305 p.

Estatuto da Criança e do Adolescente. Lei no 8.069, de 13 de junho de 1990.

Lei de Diretrizes e Bases da Educação Nacional. Lei nº 9394, de 20 de

dezembro de 1996. Dispõe sobre as Diretrizes e Bases da Educação Nacional. Brasília, DF: MEC, 1996.

Ministério da Educação e do Desporto. Secretaria de Educação Básica.

Parâmetros Nacionais de Qualidade para a educação infantil. v 1 e 2. Brasília, DF: MEC/SEB, 2009.

Parecer CNE/CEB 020/2009; Resolução CNE/CEB N. 5/2009. Diretrizes

Curriculares Nacionais para a Educação Infantil. Brasília, DF: Conselho Nacional de Educação/Câmara da Educação Básica, 2009.

Lei $n^{\circ} 12.796$ de 04 de abril de 2013. Altera a Lei $n^{\circ} 9.394$ de 20 de dezembro de 1996-LDB. Brasília: 2013.

BITTAR, M; SILVA, J.; MOTA, M. A .C. Formulação e implementação da política de educação infantil no Brasil. In: Educação infantil, política, formação e prática docente. Campo Grande, MS: UCDB, 2003.

BRANDÃO. Carlos da Fonseca. A educação infantil no Plano Nacional de Educação: a questão da oferta e do atendimento. In: PASCHOAL, Jaqueline. D. (Org.). Trabalho pedagógico na educação infantil. Londrina, PR: Humanidades, 2007. p. 77-86.

CAMPOS. M. M. FULLGRAF, J.; WIGGERS, V. A Qualidade da educação infantil brasileira: alguns resultados de pesquisa. Cadernos de Pesquisa, São Paulo, v.36, n.127, p.87-128, jan./abr. 2006.

CORRÊA. Bianca, C. Considerações sobre qualidade na educação infantil. Cadernos de Pesquisa, n. 119, julho/ 2003. p. 85-112.

DAHLBERG, Gunilla. MOSS Peter. PENCE, Alan. Qualidade na educação da primeira infância: perspectivas pós-modernas. trad. Magda França Lopes. Porto Alegre: Artmed, 2003.

FERREIRA, Maria C. Rossetti (et al). As leis e a educação infantil. In: FERREIRA, Maria C. Rossetti (org). Os fazeres na educação infantil. 2 ed. São Paulo: Cortez, 2000. p. 183 191.

KRAMER, Sonia. A política do pré-escolar no Brasil: a arte do disfarce. 5. ed. São Paulo: Cortez, 1995.

MACHADO, Maria Lucia de A. (org.). Educação infantil em tempos de LDB. São Paulo: FCC/DPE, 2000.

NASCIMENTO. Maria L. Algumas considerações sobre a infância e as políticas de educação infantil. Educação \& Linguagem • v. 14 • n. 23/24 146-159, jan.-dez. 2011.

OLIVEIRA; Zilma de Moraes Ramos; RUBIANO, Márcia R. Bonanganba. Um estudo das perspectivas para a educação infantil a partir da nova LDB. In: MACHADO, Maria Lucia 
de A. (org.). Educação infantil em tempos de LDB. São Paulo: FCC/DPE, 2000. p. 4150 .

OLIVEIRA. Zilma Moraes R. Educação infantil: fundamentos e métodos. São Paulo: Cortez, 2002. (Coleção Docência em Formação).

ROSEMBERG, Fúvia. Sísifo e a educação infantil brasileira. Pro-Posições - vol. 14, N. 1 (40) - Jan/abr. 2003. p. 177-194.

SAVIANI. Dermeval. A educação na Constituição Federal de 1988: avanços no texto e sua neutralização no contexto dos 25 anos de vigência. RBPAE - v. 29, n.2, p. 207-221, mai/ago. 2013.

ZABALZA, M. A. Qualidade em educação infantil. Porto Alegre: Artmed, 1998.

Notas

${ }^{1}$ Doutora em Educação pela Universidade Estadual de Maringá. Professora do Departamento de Educação da Universidade Estadual de Londrina.

${ }^{2}$ Professor Livre-docente do Departamento de Educação da UNESP- Assis e do Programa de Pós-graduação em Educação da UNESP- Marília.

${ }^{3}$ O presente estudo é resultado do Pós Doutorado realizado no Departamento de Educação da UNESP- AssisSão Paulo-Brasil no ano de 2014.

${ }^{4}$ A Lei ${ }^{\circ} 11.114 / 2005$, altera os artigos 6º 30, 32 e 87 da Lei ${ }^{\circ}$ 9.394, de 20 de dezembro de 1996 (LDB), com o objetivo de tornar obrigatório o início do ensino fundamental aos seis anos de idade. Posteriormente a essa determinação legal, foi sancionada a Lei $n^{\circ} 11.274$, de 6 de fevereiro de 2006, que determinou que o Ensino Fundamental no Brasil passasse a ter duração de nove anos a partir dos seis anos de idade.

${ }^{5}$ De acordo com Nascimento (2011) isso ocasionou a entrada das crianças de seis anos de idade no ensino fundamental, por meio da Lei 11.274/06, que instituiu o ensino fundamental de nove anos.

${ }^{6}$ A Lei ${ }^{\circ} 12.796$ de 04 de abril de 2013, que altera a Lei $n^{\circ} 9.394$ de 20 de dezembro de 1996-LDB, destaca em seu artigo $4^{\circ}$, inciso I: educação básica obrigatória e gratuita dos quatro aos dezessete anos de idade da seguinte forma: a)pré-escola; b) ensino fundamental; c) ensino médio.

${ }^{7}$ Embora não seja objetivo desse artigo discutir se é plausível ou não a obrigatoriedade de matrícula para a faixa etária de zero a três anos, reitera-se o direito da criança à educação desde o nascimento, conforme previsto na LDB de 1996.

${ }^{8}$ De acordo com o MEC (2006) esse documento foi organizado por representantes dos Conselhos de educação de todos os estados e do Distrito Federal, de consultores e especialistas na área, sob a coordenação de dirigentes do MEC.

${ }^{9}$ O primeiro volume discute aspectos relevantes como: concepção de criança, de educação infantil, legislação e trajetória histórica do debate da qualidade nas instituições de atendimento à criança. O segundo volume aborda as competências dos sistemas de ensino e caracterização das escolas infantis a partir de definições legais e, na sequência apresenta os parâmetros de qualidade com o intuito de estabelecer uma referência nacional que subsidie os sistemas na discussão e implementação de parâmetros de qualidade locais.

${ }^{10}$ A primeira versão das Diretrizes foi aprovada no ano de 1999, sendo revisada e atualizada uma década depois, em 2009.

${ }^{11} \mathrm{Na}$ mitologia grega Sísifo, filho do rei Éolo e Enarete, era considerado o mais astuto de todos os mortais. Mestre da malícia ele entrou para a tradição como um dos maiores ofensores dos deuses. Por isso foi condenado por toda a eternidade, rolar uma grande pedra de mármore até o cume de uma montanha, sendo que toda vez que ele estava quase alcançando o topo, a pedra rolava novamente montanha abaixo até o ponto de partida, por meio de uma força irresistível, invalidando completamente o duro esforço realizado.

${ }^{12}$ De acordo com Rosemberg (2003) a implantação da proposta foi interrompida com a administração federal em 1994, pelo governo Fernando Henrique Cardoso, que incorporou, no plano das políticas econômicas, orientações do FMI e, no plano das políticas educacionais, orientações do Banco Mundial.

Recebido: junho-15 Aprovado: dezembro-15 